\title{
Life history traits and demographic parameters in the Keratella cochlearis (Rotifera, Monogononta) species complex
}

\author{
Adam Cieplinski $[$ Ulrike Obertegger • Thomas Weisse
}

Received: 18 October 2017/Revised: 25 December 2017/ Accepted: 27 December 2017/Published online: 13 January 2018 (C) The Author(s) 2018. This article is an open access publication

\begin{abstract}
A recent study based on DNA taxonomy indicated that the widespread rotifer Keratella cochlearis comprises several evolutionarily significant units (ESUs). Identification of ESUs based on DNA taxonomy alone is problematic and usually requires morphological, demographic, and/or ecological evidence. We isolated three haplotypes belonging to two ESUs of $K$. cochlearis and conducted life table experiments to investigate if this genetic diversity is reflected in demography. We found significant differences between haplotypes in life history traits (average lifespan, number of offspring, and percent of rejected eggs) and in demographic parameters (instantaneous growth rate, generation time, and net
\end{abstract}

Electronic supplementary material The online version of this article (https://doi.org/10.1007/s10750-017-3499-2) contains supplementary material, which is available to authorized users.

Handling editor: Diego Fontaneto

A. Cieplinski $(\bowtie) \cdot$ U. Obertegger

Department of Sustainable Agro-ecosystems and

Bioresources, Research and Innovation Centre,

Fondazione Edmund Mach (FEM), Via E. Mach 1,

38010 San Michele all'Adige, TN, Italy

e-mail: a.p.cieplinski@gmail.com

A. Cieplinski - T. Weisse

Research Department for Limnology, Mondsee,

University of Innsbruck, Mondseestraße 9,

5310 Mondsee, Austria reproductive rate of the populations). During the experiments, all the haplotypes produced abnormal females with a deformed lorica, which was never reported before in $K$. cochlearis. We also report the first case of an amphoteric female (producing both females and males) in $K$. cochlearis. We hypothesize that $K$. cochlearis haplotypes and thus ESUs may exhibit niche differentiation through their different life histories. The link between demographic parameters of $K$. cochlearis and niche utilization requires further research.

Keywords Life table $\cdot$ Cryptic species $\cdot$ Abnormal females $\cdot$ Rotifers $\cdot$ Lake Tovel

\section{Introduction}

Rotifers are among the most abundant planktonic metazoans and constitute a crucial link between lower and higher trophic levels in most freshwater ecosystems around the world (Wallace et al., 2006). Rotifer biodiversity has been studied for over two hundred years, and so far about 2000 species have been described (Koste \& Hollowday, 1993; Segers \& De Smet, 2008). With the advent of molecular techniques and the introduction of DNA taxonomy, many rotifer species, traditionally considered as one species, proved to be complexes of cryptic species. Cryptic 
species, defined as genetically distinct but morphologically difficult-to-distinguish species (Gomez et al., 2002; Fontaneto et al., 2009; Birky et al., 2011; Obertegger et al., 2012, 2014; Cieplinski et al., 2017), appear to be widespread among both microorganisms and macroorganisms and have been reported in many groups such as protists (Foissner, 2006), ants (Fournier et al., 2012), harvestmen (Arthofer et al., 2013), and rotifers (Gomez \& Snell, 1996; Gomez et al., 2002; Fontaneto et al., 2009; Birky et al., 2011; Obertegger et al., 2012, 2014; Cieplinski et al., 2017). According to the niche conservatism theory, the closer the related species are, the more profound is their niche conservatism (i.e., a higher tendency to retain their ancestral traits) and the stronger is their competition (e.g., Darwin, 1859; Violle et al., 2011). Therefore, cryptic species should show strong interspecific competition and little co-existence (Wiens \& Graham, 2005; Losos, 2008; Violle et al., 2011). However, coexistence of closely related species is a difficult-toexplain phenomenon (Leibold \& McPeek, 2006), but has been observed in nearly $60 \%$ of rotifer complexes (Gabaldón et al., 2017). Yet, especially with small aquatic organisms we can never fully account for the n-dimensionality of the species niche, and, therefore, inferences about real co-existence are difficult.

Evidence is growing that cryptic species in rotifers often have different life history traits despite their close phylogenetic relationship and that these differences may play a role in their co-existence in the same environment (Gabaldón et al., 2015). Consequently, our knowledge on biodiversity, biogeography, and ecology of certain species might be biased because several cryptic species with different ecological requirements and characteristics are lumped into one species. Differences in life histories of closely related species that are linked to niche differentiation may thus add to the co-existence and evolution of cryptic species (Angert et al., 2009; Montero-Pau et al., 2011). Therefore, analyses of life histories in cryptic species complexes may help understand competitive abilities between those species.

Life table experiments represent one of the most widespread methods to study life history traits and population dynamics (King, 1970; Allan, 1976; Walz, 1983, 1987; Gribble \& Welch, 2013; Xi et al., 2013; Xiang et al., 2016a, b). Life history traits are those parameters that are directly derived from the life table of an organism (Stearns, 1992). Demographic parameters (also known as "population parameters", "population traits", etc.) are the key parameters of population dynamics (e.g., instantaneous growth rate, net reproductive rate, and generation time) (Begon et al., 1996). Various studies reported interspecific differences in life history traits for several rotifer species and cryptic species in response to abiotic factors such as salinity or temperature. Temperature is one of the most important abiotic factors influencing life histories of rotifers (Bottrell et al., 1976). Gabaldón et al. (2015) showed that the brackish water cryptic species Brachionus manjavacas exhibitsirrespective of salinity-higher growth rates than its sibling cryptic species B. plicatilis. Gabaldón and Carmona (2015) demonstrated that asexual females of B. manjavacas have higher survival rates in both middle and old age classes and, consequently, a longer mean lifespan than asexual females of $B$. plicatilis from the same lake. In spite of this demographic advantage of $B$. manjavacas with respect to $B$. plicatilis, the two cryptic species can co-exist stably (Gomez et al., 2002, 2007). Ciros-Pérez et al. (2001) reported different intrinsic growth rates in three sympatric cryptic species of the $B$. plicatilis species complex that were cultured at the same temperatures. Similarly, demographic parameters were different for eight closely related Chinese populations of $B$. calyciflorus exposed to different temperatures, and these differences were linked to adaptations of populations to different environmental conditions (Ma et al., 2010).

Life history traits and demographic parameters are also influenced by biotic factors such as food quality (Korstad et al., 1989) and quantity (Robertson \& Salt, 1981; Xi \& Huang, 1999; Sarma et al., 2001). Hu and $\mathrm{Xi}$ (2008) showed that the intrinsic growth rate, generation time, and average lifespan of two strains of B. plicatilis and one strain of B. calyciflorus were all significantly different under different food regimes. Differences in life history traits and demographic parameters were observed not only between cryptic species inhabiting the same environment (e.g., Gabaldón et al., 2015) but also between geographically isolated populations of the same species of B. calyciflorus (Wang et al., 2014).

Compared to the well-studied Brachionus spp., little is known about the life history of the freshwater rotifer Keratella cochlearis (Gosse, 1851). This is astounding considering that $K$. cochlearis is globally 
distributed in lakes and ponds and is one of the most common pelagic species worldwide (Pourriot, 1965). One of the reasons why $K$. cochlearis is understudied in contrast to Brachionus spp. is because it is much more difficult to culture (Lindström \& Pejler, 1975; Pourriot, 1980; Stemberger, 1981). Among the few existing studies on $K$. cochlearis (Edmondson, 1965; Zimmermann, 1974; Walz, 1983; Gilbert \& Stemberger, 1985; Walz, 1983, 1986, 1987), those performed by Walz $(1983,1987)$ are the most extensive ones. This author reported changes in the life history of $K$. cochlearis dependent on temperature and food regimes. Recently, the existence of a cryptic $K$. cochlearis species complex has been hypothesized by Cieplinski et al. (2017) based on DNA taxonomy; these authors also demonstrated that it is possible to delimit several distinct evolutionarily significant units (ESUs) based solely on morphological differences between ESUs.

Here, we investigated differences in life histories between three haplotypes of $K$. cochlearis. These haplotypes belong to two putative evolutionarily significant units (ESUs)_ESU 3 and ESU 6 of $K$. cochlearis, described in Cieplinski et al. (2017) and in Obertegger et al. (2017). We hypothesized different life history traits and demographic parameters in at least two haplotypes of $K$. cochlearis belonging to different ESUs, assuming that the existence of cryptic species was correctly inferred by DNA taxonomy.

\section{Materials and methods}

Rotifer isolation, haplotypes, and ESU

We focused on three haplotypes belonging to two ESUs that were discriminated based on their mitochondrial cytochrome oxidase subunit 1 gene (COI) by Cieplinski et al. (2017). Discrimination for these ESUs and haplotypes was later confirmed by phylogenetic analyses with a nuclear marker (internal transcribed spacer 1, ITS1) by Obertegger et al. (2017). These haplotypes were isolated from lakes Tovel, Kaltern, and Terlago (N. Italy) during a detailed sampling conducted between 2013 and 2015 (for details, see Cieplinski et al., 2017).

For simplicity, we refer to two ESUs as "ESU 3" and "ESU 6" as previously described by Cieplinski et al. (2017) and to the haplotypes as "Hap A" (belonging to ESU 6), "Hap B," and "Hap C" (both belonging to "ESU 3," Table 1). The sampled lakes, although geographically relatively close, represent different environmental conditions (Table 2). Lake Tovel, despite its mid-altitude location, has the characteristics of an alpine lake (Obertegger \& Flaim, 2015), while Lakes Kaltern and Terlago are lowland lakes embedded in an agricultural landscape.

The three haplotypes were regularly observed during the monthly sampling period in 2014 (supplementary material Table s1). Hap B was isolated from Lake Kaltern but was also found once in Lake Vahrn (supplementary material Table s1). Moreover, Hap A was present in Lake Tovel, Hap B in Kaltern, and Hap $\mathrm{C}$ in Lake Terlago in all samples indicating that these particular haplotypes are not only temporarily occurring but are in fact parts of permanent $K$. cochlearis communities in the studied lakes (Cieplinski et al., 2017).

Samples were taken at the deepest site of each lake with a $50-\mu \mathrm{m}$ Wisconsin-type plankton net. Rotifers were collected from Lake Terlago on September 23, 2014 and from both Tovel and Kaltern on March 2, 2015. One clonal culture per lake was established from a single female collected from that lake and continuously maintained in the laboratory. Clonal rotifer cultures were kept inside an incubator in 6-well plates (Biomedica, Vienna) in modified WC medium (Guillard \& Lorenzan, 1972) at an average temperature of $14.5^{\circ} \mathrm{C}$ and a $16: 8 \mathrm{~h}$ light-dark photoperiod. The same medium was also used to cultivate Cryptomonas sp. strain no. 26.80 obtained from the culture collection of algae in Göttingen, Germany. This Cryptomonas sp. served as the only food source for all rotifer clones before and during the life table experiments. Algal concentration was measured with an electronic particle counter (CASY 1-Model TTC, Schärfe System) according to Weisse and Kirchoff

Table 1 Haplotypes used for life table experiments: Haplotype, COI-ESU (terminology for haplotypes and COI-ESUs according to Cieplinski et al., 2017), ITS1-ESU (terminology for ESUs according to Obertegger et al., 2017), and Hap (terminology for haplotypes in this study)

\begin{tabular}{lllll}
\hline Lake & Haplotype & COI-ESU & ITS1-ESU & Hap \\
\hline Tovel & h30 & ESU 6 & ESU $\alpha$ & A \\
Kaltern & h5 & ESU 3 & ESU $\beta$ & B \\
Terlago & h14 & ESU 3 & ESU $\beta$ & C \\
\hline
\end{tabular}


Table 2 Environmental data of sampled lakes: altitude (alti; $\mathrm{m}$ above sea level), area (ha), depth (m), mean summer surface temperature (temp; ${ }^{\circ} \mathrm{C}$ ), conductivity (cond; $\mu \mathrm{S} \mathrm{cm}{ }^{-1}$ ), and trophic state (eutrophic—eu; mesotrophic—meso; oligotrophic-oligo)

\begin{tabular}{|c|c|c|c|c|c|c|c|c|}
\hline Lakes & Geographical coordinates & Alti & Area & Depth & Temp & Cond & $\mathrm{pH}$ & Trophic state \\
\hline Tovel & $46^{\circ} 15^{\prime} 43.2432^{\prime \prime} \mathrm{N} 10^{\circ} 56^{\prime} 41.6472^{\prime \prime} \mathrm{E}$ & 1178 & 38.2 & 39 & 15 & 192 & 7.9 & oligo \\
\hline Kaltern & $46^{\circ} 22^{\prime} 43.1724^{\prime \prime} \mathrm{N} 11^{\circ} 15^{\prime} 50.2092^{\prime \prime} \mathrm{E}$ & 215 & 147 & 5 & 18 & 507 & 8.3 & meso \\
\hline Terlago & $46^{\circ} 5^{\prime} 56.3568^{\prime \prime} \mathrm{N} 11^{\circ} 3^{\prime} 21.258^{\prime \prime} \mathrm{E}$ & 414 & 11.9 & 10 & 23 & 289 & 8 & $\mathrm{eu}$ \\
\hline
\end{tabular}

(1997). Most complete life table experiments with $K$. cochlearis were performed by Walz $(1983,1987)$ on specimen coming from the small pond Fasaneriesee in southern Germany. Walz $(1983,1987)$ reported $15{ }^{\circ} \mathrm{C}$ as the optimum temperature for his cultures. Therefore, we conducted all experiments at $15^{\circ} \mathrm{C}$.

Initially, many more clones and haplotypes were selected for culturing for each of the ESUs, also including various haplotypes from the same lakes. However, owing to general difficulties in culturing $K$. cochlearis, we were not able to maintain them in cultures and most of the clones died regardless of culturing efforts.

\section{Life table experiments}

Life table experiments for all three haplotypes of $K$. cochlearis were performed using exactly the same experimental setup, including food concentration, temperature, and light conditions. Depending on the size of the wells, we placed two to four flakes of cetyl alcohol on the surface of each well to reduce surface tension (see Desmarais, 1997; Stelzer, 1998), and thus to lower the probability that rotifers were caught in the surface film.

Each experiment comprised three phases:

(1) standardization-performed in 30 Petri dishes to standardize conditions and to minimalize maternal effects;

(2) synchronization-performed in 24-well plates for female synchronization;

(3) life table experiment-performed in 96-well plates, similarly to the experiment conducted by Walz (1983).

In monogonont rotifers, a switch from asexual to sexual reproduction is generally attributed to the accumulation of mixis-inducing proteins released into the environment by the rotifers themselves (Stelzer \& Snell, 2003; Snell et al., 2006). Sun and Niu (2012) observed for B. calyciflorus that maternal crowding of amictic (asexually reproducing) females can enhance the propensity of offspring to produce mictic (sexually reproducing) females. Therefore, the main purposes of the acclimation period (phase 1) were to minimize the probability of mictic female appearance in phases (2) and (3) and to standardize the starting conditions for all three haplotypes. Because the exact sex-inducing female density has not yet been described for $K$. cochlearis, the number of females used for phase (1) was based on earlier observations in our laboratory. The duration of phase (1) was long enough to rear several generations of rotifers. To initiate phase (1), five individuals were placed into 30 Petri dishes containing $30 \mathrm{~mL}$ of medium with abundant food (Cryptomonas sp. $>30,000$ cells $\mathrm{mL}^{-1}$ ) and cultured for approximately 14 days. Rotifer abundance was monitored until the total number of rotifers in all dishes reached more than $\sim 300$ individuals, which was a prerequisite to start phase (2).

For phase (2), single young females from phase (1) were pipetted into eight 24-well plates containing $2 \mathrm{~mL}$ of medium with Cryptomonas sp. (>30,000 cells $\left.\mathrm{mL}^{-1}\right)$. The criteria for selecting young females were transparency, smaller body size than adult females, and lack of eggs. These features allowed us to discriminate young females from adult ones that recently gave birth and carried no eggs. Each rotifer during phase (2) was observed two times per day, in the morning and late afternoon, to record the most proximate time of offspring production. The general purpose of phase (2) was to produce many females of similar age whose offspring born at approximately the same time were then used for phase (3); accordingly, we used the term "female synchronization" for phase (2). Newly hatched offspring from the 1st clutch (i.e., a cohort) of phase (2) females were immediately removed and used for phase (3). Phase (2) lasted for a period of approximately 14 days, which was sufficiently long enough to ensure that females produced 
several generations of offspring. Only offspring from the same $1^{\text {st }}$ clutch were selected (possible due to the synchronization of their mothers) for the life table experiment (phase 3) to further standardize initial conditions. For phase (3), single females born at approximately the same time were placed into wells of a 96-well plate containing $230 \mu \mathrm{L}$ of medium and food solution with Cryptomonas sp. $>30,000$ cells $\mathrm{mL}^{-1}$. The initial number of females was always 96 . Rotifers were observed twice per day to record the number of eggs, dead individuals, and the number and sex of offspring. All specimens were transported to fresh medium with food every fourth day, which represented a compromise between culture maintenance and preventing specimen loss due to death by mechanical interference. Newly hatched juveniles were removed immediately and discarded. Apart from females and males, abnormally swimming and nonloricated individuals were also counted; these specimens were called abnormal females. Amictic (parthenogenetic) eggs that did not hatch and instead decomposed in the course of several days at the bottom of the Petri dish were also counted and called rejected eggs.

Analyses of life table data

The life history traits and demographic parameters were calculated based on a sample size of 96 individuals for each haplotype. All females, irrespective of offspring production and all offspring, females, males, and abnormal females were included in calculations. Demographic parameters were calculated according to Birch (1948) and Walz (1983): average lifespan $(L)$ was reported in days, survivorship $\left(l_{x}\right)$ was the percentage of surviving females on day $x$, agespecific birth rate $\left(m_{x}\right)$ was the fraction of all the surviving offspring on day $x$, and age-specific fecundity rate $\left(l_{x} m_{x}\right)$ was the product of $l_{x}$ and $m_{x}$.

The net reproduction rate $\left(R_{0}\right)$ was the sum of $l_{x} m_{x}$ over the entire experiment:

$R_{0}=\Sigma l_{x} m_{x}$

Generation time $(T)$ is the time from hatching from an egg to producing an offspring and is calculated according to
$T=\ln \left(R_{0}\right) / r$

The instantaneous growth rate per day $(r)$ was estimated by solving Lotka's equation (Lotka, 1907) iteratively, assuming exponential growth (see Birch, 1948):

$\sum_{x \geq 1} e^{r(x+0.5)} l_{x} m_{x}$

where $e$ is the Euler constant (2.71828), $x$ the age in days, $l_{x}$ the age-specific survival rate, (i.e., the proportion of surviving females at day $x$ ), relative to the initial number of females, and $m_{x}$ the age-specific fecundity rate, i.e., the mean number of offspring produced on day $x$ by a female of age $x$.

In the case of $R_{0}, T$, and $r$, bootstrapping was used to obtain estimates of means and standard deviation. Bootstrapping was done by randomly resampling the same sampling size $(n=96)$ with replacement from the original sample (Quinn \& Keough, 2002). Bootstrapping with replacement generates robust representative statistics (Dixon, 2002) as shown for growth rates of cladocerans (Meyer et al., 1986). Here, we used 1000 bootstrapped samples.

Mean values of all life table parameters were tested for significant differences between haplotypes by nonparametric Kruskal-Wallis one-way analysis of variance. For pairwise comparisons of values which did not show normal distribution, the Dunn's post hoc test (95\% family-wise confidence levels) was used. Normal distribution was found only for $T$, and therefore in this case ANOVA was used for analysis of variance and Tukey's post hoc test (95\% family-wise confidence levels) was used for pairwise comparisons. All statistical analyses were performed using R 3.4.1 (R Core Team, 2017).

\section{Results}

Life history traits and demographic parameters of different haplotypes and ESUs

All females (i.e., amictic, mictic, females producing abnormal females) and all the offspring (females, males, and abnormal females) were included in the analyses of life table data. Excluding mictic females or females producing abnormal females did not change the results in a meaningful way (supplementary 
material Table s2). All three haplotypes showed statistically significant differences in all demographic parameters except for L (Table 3). Specifically, Hap A produced more offspring (average number of offspring: 8.1 for Hap A, 2.0 for Hap B, 3.3 for Hap C) and showed a lower percentage of rejected eggs (2.15\% with respect to $12.61 \%$ for hap B and $9.67 \%$ for Hap C) and a higher L compared to Hap B and Hap C (17.0 days with respect to 11.3 and 13.4 days; Table 3). Males were only observed in Hap A (Table 3). All haplotypes showed positive $r$ with Hap A showing the highest $r$ and Hap B the lowest r (0.23 and 0.08 days, respectively) (Table 3 ). $\mathrm{T}$ was the shortest in Hap C (7.99 days) and the longest in Hap A (9.22 days); there were significant differences between all haplotypes. Similarly, $R_{0}$ was significantly different between all haplotypes.

Age-specific survival rate $\left(l_{x}\right)$ of Hap $\mathrm{C}$ decreased less, relative to Hap B or Hap A during the first nine days (Fig. 1). After this initial phase, Hap C showed a distinctly faster decline than Hap A and Hap B. Furthermore, after day 23 no specimens of Hap $C$ were alive, in contrast to Hap A and Hap B. The shape of the $l_{x}$ curve for Hap A and Hap B was similar, but Hap A specimens lived longer than Hap B specimens.
Hap A showed higher $l_{x} m_{x}$ and $m_{x}$ values and more frequent and regular cyclical patterns (Fig. 2A1, A2) than Hap B and Hap C (Fig. 2B1, B2; Fig. 2C1, C2). In all three haplotypes, a sharp initial peak appeared after 3 to 4 days, corresponding to the time needed for specimens to reach maturity. Due to increasing mortality of the mothers, the peak height declined in all experiments until the whole population had died.

Occurrence of abnormal and amphoteric females in experiments and in routine cultures

Amictic females showing an undeveloped, non-rigid lorica, impaired swimming abilities, and short (maximum 1 day) lifespan were classified as abnormal females (Fig. 3). We exclude the possibility that these females were males because they were larger than males and had visible and moving trophi (Fig. 3c). Furthermore, both penis and setae were absent in the photographed females. The lorica of these deformed females lacked structures such as plates, ridges, and ornamentation. However, a small, deformed posterior spine was present (Fig. 3e). In routine cultures, such deformed females were very rare. During the experiments, the highest number of abnormal females was

Table 3 Demographic parameters reported for COI haplotypes: lifespan (L; days), instantaneous growth rate of the population ( $r$; $\left.\mathrm{d}^{-1}\right)$, generation time (T; days), and net reproductive rate $\left(R_{O}\right)$

\begin{tabular}{|c|c|c|c|}
\hline & Hap A & Hap B & Hap C \\
\hline COI-ESU & 6 & 3 & 3 \\
\hline$L$ (days) & $\begin{array}{l}17.0^{\mathrm{aa}} \pm 8.49 \\
17.5\end{array}$ & $\begin{array}{l}11.3^{\mathrm{bb}} \pm 6.94 \\
11.75\end{array}$ & $\begin{array}{l}13.4^{\mathrm{bb}} \pm 3.35 \\
13.5\end{array}$ \\
\hline Average number of offspring & $\begin{array}{l}8.1^{\mathrm{aa}} \pm 4.52 \\
9.5\end{array}$ & $\begin{array}{l}2.0^{\mathrm{bb}} \pm 2.02 \\
2\end{array}$ & $\begin{array}{l}3.3^{\mathrm{cc}} \pm 1.38 \\
3\end{array}$ \\
\hline$r\left(\mathrm{~d}^{-1}\right)$ & $\begin{array}{l}0.23^{\mathrm{a}} \pm 0.001 \\
0.228\end{array}$ & $\begin{array}{l}0.08^{\mathrm{b}} \pm 0.001 \\
0.077\end{array}$ & $\begin{array}{l}0.15^{\mathrm{c}} \pm 0.001 \\
0.149\end{array}$ \\
\hline$T$ (days) & $\begin{array}{l}9.22^{\mathrm{aa}} \pm 0.02 \\
9.22\end{array}$ & $\begin{array}{l}9.24^{\mathrm{bb}} \pm 0.05 \\
9.24\end{array}$ & $\begin{array}{l}7.99^{\mathrm{cc}} \pm 0.03 \\
7.99^{\circ}\end{array}$ \\
\hline$R_{0}$ & $\begin{array}{l}8.2^{\mathrm{a}} \pm 0.05 \\
8.16\end{array}$ & $\begin{array}{l}2.0^{\mathrm{b}} \pm 0.03 \\
2.03\end{array}$ & $\begin{array}{l}3.3^{\mathrm{c}} \pm 0.02 \\
3.29\end{array}$ \\
\hline Number of female offspring (total) & 769 & 194 & 302 \\
\hline Number of male offspring (total) & 7 & 0 & 0 \\
\hline Number of abnormal females (total) & 1 & 1 & 14 \\
\hline$\%$ of abnormal females in all offspring & $0.64^{\mathrm{ac}}$ & $0.51^{\mathrm{a}}$ & $4.43^{\mathrm{c}}$ \\
\hline$\%$ of rejected eggs & $2.15^{\mathrm{aa}}$ & $12.61^{\mathrm{bb}}$ & $9.67^{\mathrm{b}}$ \\
\hline
\end{tabular}

Reported are mean \pm standard deviation (upper row values) and median (lower row value) for each parameter; all values followed by different superscripts are statistically different; values followed by a single superscript are statistically different at $P<0.05$, and values followed by double superscript are statistically different at $P<0.001$. COI-ESU coding is according to Cieplinski et al. (2017) 


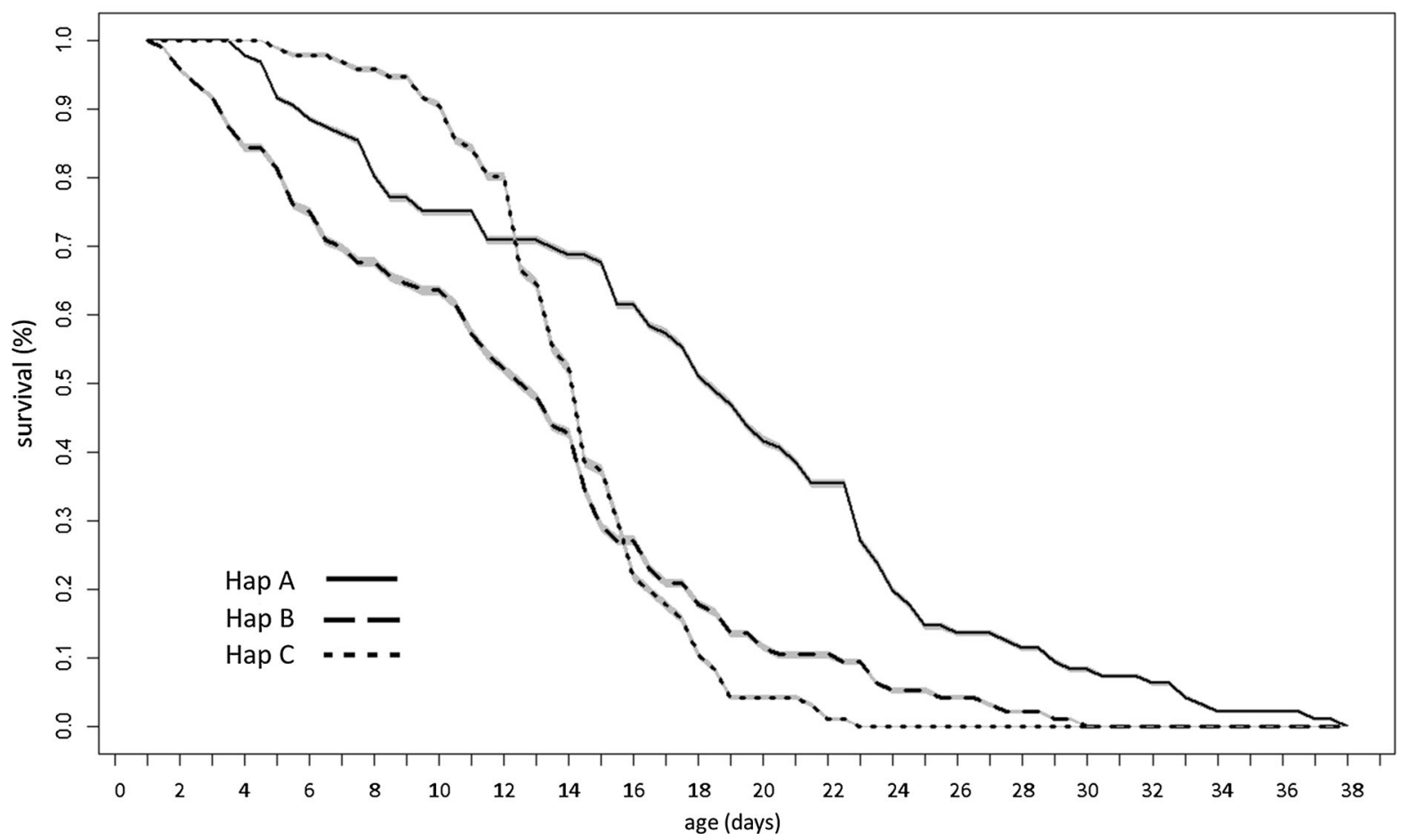

Fig. 1 Age-specific survivorship $\left(l_{x}\right)$ for Hap A, Hap B, and Hap C. Hap A belongs to ESU 6 and Hap B and C to ESU, and 3. 95\% confidence intervals are shown as shaded area, but are quite small

recorded for Hap C with a total of 14 specimens (Table 3). For Hap A, one amphoteric female was observed. This female produced two female offspring on days 5 and 10, and 6 male offspring on several days (i.e., 6, 8, 11, 12, 14, 19). No other amphoteric females have been observed in our cultures. The percent of amphoteric females was therefore $0.35 \%$ for all the rotifers (288 neonates for three haplotypes together). We did not observe any morphological differences between the single amphoteric female and amictic females.

\section{Discussion}

Differences in life history traits and demographic parameters in cryptic species of K. cochlearis

The total diversity of haplotypes of $K$. cochlearis within one ESU and the diversity of ESUs is unknown and requires further research. Even though our study did not evaluate intra-haplotype variability of demography, it is the first study that investigates demographic differences in haplotypes in rotifer species other than Brachionus. We demonstrated that genetically different (see Cieplinski et al., 2017) haplotypes of $K$. cochlearis differ also demographically. Combining molecular and demographic data for cryptic species is essential to correctly delimit species using an integrative taxonomy approach recommended by Schlick-Steiner et al. (2010), Fontaneto et al. (2015), and Papakostas et al. (2016). Very few experimental studies on $K$. cochlearis exist; moreover, they did not consider cryptic diversity. These earlier studies focused on the instantaneous rate of population growth (Table 4). Only Walz $(1983,1987)$ provided complete life table data for $K$. cochlearis, and thus most of our comparisons relate to his studies. The instantaneous rate of population growth $(r)$ is a comprehensive parameter and is often considered a proxy for fitness, representing the ability of a rotifer population to grow and prosper in an environment (Campillo et al., 2011). In our study, $r$ values of the three haplotypes mostly fell within the range known from previous studies of $K$. cochlearis (Table 4) and were all positive, indicating population growth; 
A1

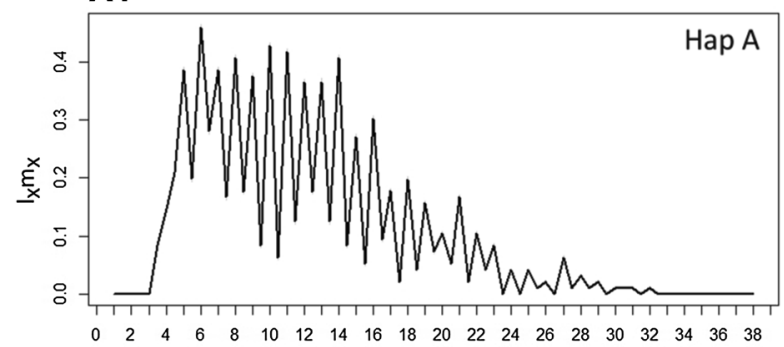

B1

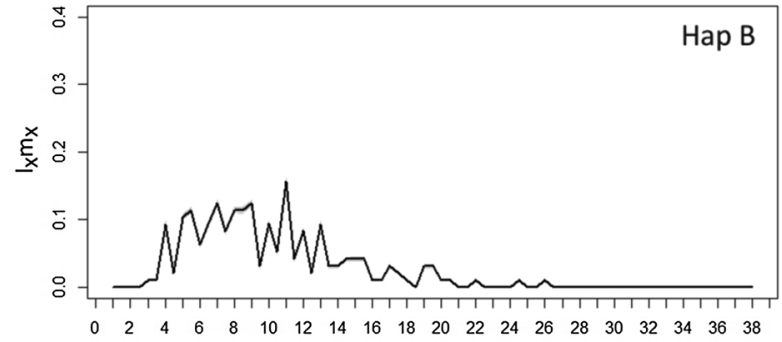

C1

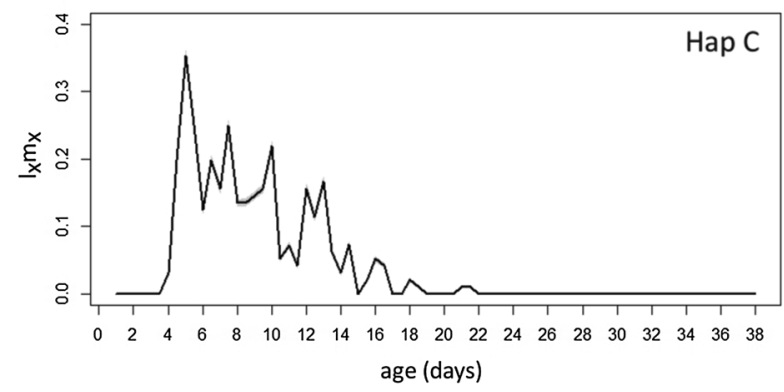

A2

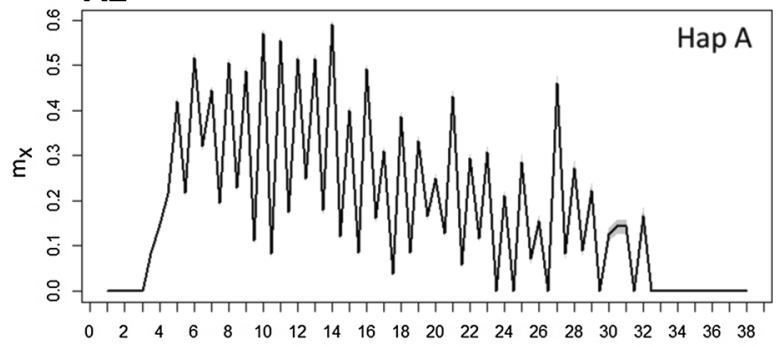

B2

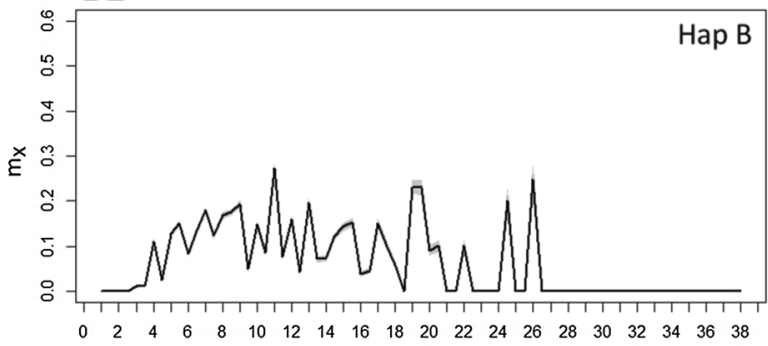

C2

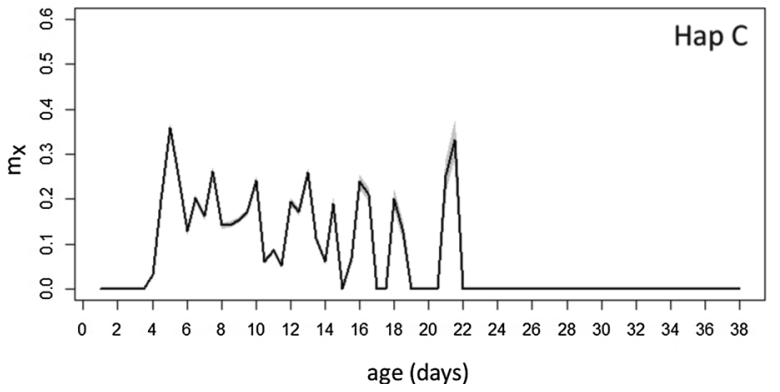

Fig. 2 Age-specific fecundity $\left(l_{x} m_{x}\right)$ and age-specific birth rate $\left(m_{x}\right)$ for Hap A (A1 and A2), Hap B (B1 and B2), and Hap C (C1 and C2). Hap A belongs to ESU 6 and Hap B and C to ESU, and 3.95\% confidence intervals are shown as shaded area, but are quite small

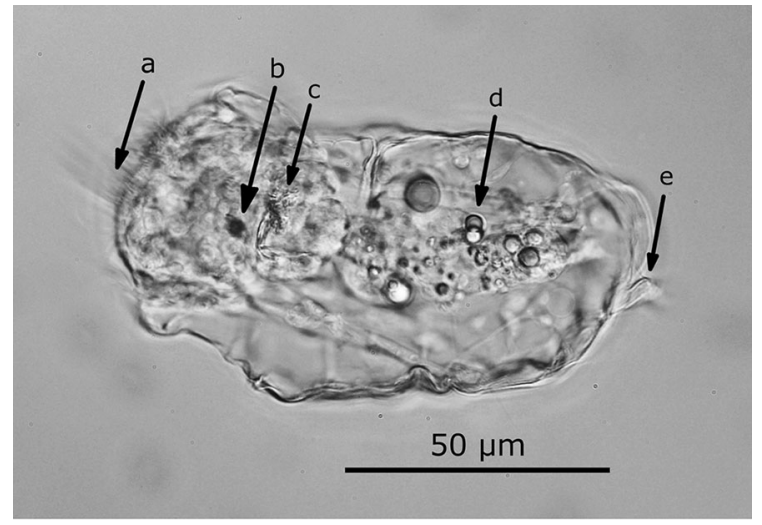

Fig. 3 Light microscopic picture in dorsal view of a deformed $K$. cochlearis female: a ciliae, b eyespot, c trophy, d lipid globules, and e deformed posterior spine. Dorsal view. Scale bar: $50 \mu \mathrm{m}$ however, we also observed the lowest $r$ value (for Hap B) ever reported for K. cochlearis. The $r$ of Hap A (0.228) was also comparable with $r$ reported by Weisse and Frahm (2001) for $K$. quadrata $(0.223 \pm 0.21$ fed with Cryptomonas sp. $>30,000$ cells $\mathrm{mL}^{-1}$ ). Walz (1995) reported slightly higher $r$ values for other Keratella species, i.e., 0.32 for $K$. quadrata, 0.3 for K. earlinae, and 0.28 for $K$. crassa.

The time span to reach reproductive maturity is indicated by the T value. Walz (1983) reported $\mathrm{T}$ for $K$. cochlearis to be 8.1 days at $15^{\circ} \mathrm{C}$; this value is slightly lower than those for Hap A and Hap B but comparable with that for Hap C. Differences in T and in $r$ between the haplotypes were also reflected by their offspring number. Correspondence between $\mathrm{T}$ and offspring number was found by Ma et al. (2010) for 
Table 4 Population parameters for $K$. cochlearis reported in various studies where food and temperature varied depending on the experimental setting: instantaneous growth rate of populations ( $r$; days), net reproductive rate $\left(R_{0}\right)$, generation time ( $T$; days), lifespan ( $L$; days), lake (refers to the lake of population's origin), lake altitude (Alti; $\mathrm{m}$ above sea level), lake depth (Depth; m), and trophic state (eutrophic-eu; mesotrophic-meso; oligotrophic_oligo)

\begin{tabular}{|c|c|c|c|c|c|c|c|c|}
\hline$r$ & $\mathrm{R}_{0}$ & $\mathrm{~T}$ & $\mathrm{~L}$ & Lake & Alti & Depth & $\begin{array}{l}\text { Trophic } \\
\text { state }\end{array}$ & Authors \\
\hline$\sim 0.17_{\mathrm{a}}$ & & & & $\begin{array}{l}\text { Windermere N. } \\
\text { Basin; } \\
\text { Windermere S. } \\
\text { Basin; } \\
\text { Esthwaite; } \\
\text { Blelham }\end{array}$ & $\begin{array}{l}39 ; \\
39 ; \\
65.2 ; \\
42\end{array}$ & $\begin{array}{l}25.1 \\
16.8 \\
6.4 ; \\
6.8\end{array}$ & all lakes eu & Edmondson (1965) \\
\hline 0.35 & & & & Sempach & 504 & 87 & $\mathrm{eu}$ & Zimmermann (1974) \\
\hline 0.095 & 2.5 & 8.1 & 15.4 & Fasaneriesee & 494 & 5.7 & $\mathrm{eu}$ & Walz (1983) \\
\hline $\begin{array}{l}0.28 \text { (food: } \\
\quad \text { Rhodomonas) }\end{array}$ & & & & Post Pond & 134 & 38 & meso & $\begin{array}{l}\text { Stemberger \& Gilbert } \\
\text { (1985) }\end{array}$ \\
\hline $\begin{array}{l}0.35 \text { (food: } \\
\text { Cryptomonas) }\end{array}$ & & & & Post Pond & 134 & 38 & meso & $\begin{array}{l}\text { Stemberger \& Gilbert } \\
\text { (1985) }\end{array}$ \\
\hline 0.3 & & & & Fasaneriesee & 494 & 5.7 & $\mathrm{eu}$ & Walz (1986) \\
\hline 0.095 & & & & Fasaneriesee & 494 & 5.7 & $\mathrm{eu}$ & Walz (1987) \\
\hline 0.214 & & & & Schöhsee & 22 & 29 & meso & Weisse \& Frahm (2001) \\
\hline 0.23 & 8.2 & 9.22 & 17.0 & Tovel; & 1178; & 39 & oligo; & This study \\
\hline 0.08 & 2.0 & 9.24 & 11.3; & Kaltern; & 215 & 5 & meso; & \\
\hline 0.15 & 3.3 & 7.99 & 13.4 & Terlago & 414 & 10 & $\mathrm{eu}$ & \\
\hline
\end{tabular}

In the present study, means were reported for demographic parameters. Please note that values are as reported in original papers

aEdmondson (1965) reports "population reproductive rate" which has a similar meaning as $r$; its value was derived from the graph

different cryptic species of $B$. calyciflorus. Walz (1995) reported $\mathrm{T}$ for $K$. quadrata to be 4.8 days at $15{ }^{\circ} \mathrm{C}$, which is comparable with $\mathrm{T}$ in our study.

Walz (1983) calculated $R_{0}=2.15$. In our study, $R_{0}$ for Hap B was 2.0 and that for Hap C was 3.29, while $R_{O}$ for Hap A was much higher. Such differences in amictic offspring production under identical culture conditions were also reported for the B. plicatilis cryptic complex (Kostopoulou \& Vadstein, 2007). Lifespan (L) reported by Walz (1983) was $15.4 \pm 1$ days at $15^{\circ} \mathrm{C}$, which is comparable to our fastest developing Hap A. Regarding reproductive curves, both $l_{x} m_{x}$ and $m_{x}$ did not overlap for Hap A and for the two other haplotypes but were almost identical between Hap B and Hap C. However, $l_{x}$ did not overlap between all haplotypes indicating differences in survivorship of all three haplotypes. This suggests that for $K$. cochlearis some demographical parameters may differ more between ESUs than between closely related haplotypes from the same ESU.
None of the haplotypes tested showed all life table parameters similar to the ones reported by Walz (1983, 1987). Large demographic differences in the cryptic species complex of $K$. cochlearis may indicate that the $K$. cochlearis populations previously described were composed of various ESUs and/or haplotypes that differed from those used in the present study.

In rotifers, the appearance of males has been associated with mixis-inducing proteins that are released by females when the population density reaches a species-specific threshold (Carmona et al., 1993; Stelzer \& Snell, 2003, 2006; Snell et al., 2006). We observed males only in Hap A, regardless of identical culture conditions for all haplotypes. We hypothesize that this could be related to different density thresholds that trigger sexual reproduction in haplotypes (or in ESUs); this issue requires further study. 
We observed some rejected, detached eggs for all the haplotypes. Keen and Miller (1977) indicated that in $K$. cochlearis amictic eggs that are always attached to their mother hatch at different intervals. This indicates that detached amictic eggs in our study were no more viable. We also excluded the possibility of those eggs being pseudo-sexual eggs (resting eggs produced in parthenogenesis) similar to those observed for K. hiemalis (Ruttner-Kolisko, 1946) and for Synchaeta pectinata (Gilbert, 1995) because these rejected, detached eggs were morphologically identical to amictic eggs and clearly decomposed after some time on the bottom of the container. Moreover, pseudo-sexual eggs have never been reported in $K$. cochlearis and neither did we observe them in our laboratory. This result is unexpected as Keen and Miller (1977) reported a hatching rate for amictic eggs of $K$. cochlearis of $100 \%$. The percent of rejected amictic (parthenogenetic) eggs did vary significantly between Hap A and Hap B and between Hap A and Hap B but not between Hap B and Hap C. Such differences in hatching rates for different cryptic species have been found for diapausing eggs. Gabaldón et al. (2015) reported that the hatching rate of diapausing eggs differs depending on salinity between different cryptic species of $B$. plicatilis and $B$. manjavacas. In our case, culture conditions were constant; therefore, we associated varying hatching rates with population differences between the haplotypes.

The pre-experiment phases (1) and (2) lowered the maternal effect related to crowding (see Lynch \& Ennis, 1983) and standardized initial conditions allowing us to observe what we interpret as phenotypic differences unrelated to culture conditions. The observed vast phenotypic and genetic diversity may result from genetically fixed, adaptive evolution (Olson-Manning et al., 2012) related to life in a fastchanging and harsh environment of alpine lakes (represented in our study by lake Tovel). Alpine lakes often experience large environmental changes within short time scales (Sommaruga, 2001), which may trigger intraspecific variation and promote changes in species composition over relatively short evolutionary time scales (Weckström et al., 2016).
Relevance of abnormal females

Abnormal and deformed females, usually appearing as a response to toxins, were reported for $K$. cochlearis by Żurek (2006), for Plationus patulus by Rios-Arana et al. (2007), and for B. calyciflorus by AlvaradoFlores et al. (2015). While the latter two studies were performed in the laboratory experimentally exposing rotifers to toxins, the former study found deformed spines in $K$. cochlearis due to exposure to sulfides or its derivates present in water of a mine impoundment. To the best of our knowledge, deformed females without induction of any toxins are not known for $K$. cochlearis. These deformed females did not show any similarity with males. Wesenberg-Lund (1923) described that any trace of an alimentary canal and trophi have never been observed in males of $K$. cochlearis (previously described as Anurae cochlearis). Moreover, as described by WesenbergLund (1923), males of $K$. cochlearis have a long flexible penis with two setae at the end, and the penis cannot be withdrawn. In the present study, the larger size, the presence of trophi, and the absence of a penis and setae let us conclude that these specimens were indeed females, not males. In our study, all three haplotypes of $K$. cochlearis produced abnormal females under standard experimental conditions. Moreover, the percent of abnormal females in Hap C was much higher than that for the other two haplotypes. We cannot exclude the possibility that the genotype of Hap $\mathrm{C}$ had some mutations leading to a higher number of abnormal females than in the case of Hap A and Hap B. Most probably, abnormal females did not reproduce because they were never observed carrying eggs and their lifespans were shorter than that of normal females. Therefore, in the long run, the occurrence of abnormal females would result in fitness reduction of the population, relative to a population that produces only fertile females per generation.

We used identical conditions for all cultures and could not identify any proximate factor triggering the occurrence of abnormal females. Therefore, we conclude that the production of deformed females was due to intrinsic factors. One possible intrinsic factor is the accumulation of deleterious mutations (Lynch et al., 1999). Henry et al. (2011) and Barraclough et al. (2007) showed that deleterious mutations are more prevalent in asexually reproducing populations. 
Furthermore, deleterious mutations can accumulate due to low genetic variance also in small, at times sexually reproducing populations (Ridley, 2008) such as in Daphnia (Berg, 2005). Therefore, differences in the occurrence of abnormal females between the haplotypes of $K$. cochlearis may reflect differential genetic variability and accumulation of mutations because our cultures have been kept for approximately 2 years in the laboratory. Furthermore, we cannot exclude the possibility that we accidently selected haplotypes prone to genetic mutations.

\section{Occurrence of amphoteric females}

Amphoteric females can produce eggs both by mitosis and meiosis, and are thus able to produce both female and male offspring (King \& Snell, 1977). Amphoteric females have only been described for six rotifer species (Rico-Martínez \& Walsh, 2013): Asplanchna herricki (Mrázek, 1897), A. priodonta (Sudzuki, 1955), Sinantherina socialis (Bogoslavsky, 1958), Conochiloides coenobasis (Bogoslavsky, 1960), A. girodi (King \& Snell, 1977), and Trochospaera solstitialis (McCullough \& Lee, 1980). Therefore, to the best of our knowledge, this is the first record on the appearance of amphoteric females in the genus Keratella. Only by careful observation of single females for longer time periods, the existence of amphoteric females can be confirmed; therefore, it is possible that also in other genera and species amphoteric females occur. In our study, we observed only one amphoteric female corresponding to $0.35 \%$ females in our population; this is similar ratio to the ratio reported by King and Snell (1977), who observed seven amphoteric females of $A$. girodi among 1386 neonates. However, Rico-Martínez and Walsh (2013) observed three amphoteric females of $S$. socialis among only 12 neonates; the exact mechanisms behind the production of amphoteric females remain unknown (Rico-Martinez \& Welsh, 2013). Therefore, more observations with different Keratella populations are required to investigate this phenomenon in more detail.

In conclusion, this is the first study on $K$. cochlearis that combines demography with genetics-based taxonomy and investigates demographic differences between $K$. cochlearis haplotypes and ESUs. The three investigated haplotypes showed large differences in almost all life history traits and demographic parameters. Furthermore, smaller (and possibly biologically less relevant) differences were recorded between the two haplotypes from ESU 3, which may point to their closer relatedness. Thus, our hypothesis of significant differences in life history parameters between different haplotypes of $K$. cochlearis was confirmed. Although widespread around the world, $K$. cochlearis is an understudied species of monogonont rotifers, probably because of difficulties in culturing. Our study includes a detailed description of $K$. cochlearis culturing methods, which may be useful for future research on this species. The occurrence of abnormal and amphoteric females in K. cochlearis deserves further investigation. Because haplotypes used in this study were collected from various lakes, it is difficult to derive any conclusions regarding possible co-existence of these haplotypes in their natural environment. Therefore, more research is needed with more $K$. cochlearis haplotypes per ESU and ESUs derived from the same lake and season.

Acknowledgements Open access funding provided by University of Innsbruck and Medical University of Innsbruck. We would like to thank Marlies Zeilinger (University of Salzburg) for help with lifetable experiments, Peter Stadler (University of Innsbruck) and Lorena Ress (FEM) for general assistance in the laboratory, and Giovanna Flaim (FEM) for her language advice in preparing the manuscript. This work was supported by FIRST PhD School Program of the Fondazione Edmund Mach (FEM) and by the "Doktoratsstipendiums NEU" scholarship from the University of Innsbruck. We also thank the Reviewers and the Guest Editors of Hydrobiologia for their suggestions that improved this article.

Open Access This article is distributed under the terms of the Creative Commons Attribution 4.0 International License (http:// creativecommons.org/licenses/by/4.0/), which permits unrestricted use, distribution, and reproduction in any medium, provided you give appropriate credit to the original author(s) and the source, provide a link to the Creative Commons license, and indicate if changes were made.

\section{References}

Allan, J. D., 1976. Life history patterns in zooplankton. The American Naturalist 110: 165-180.

Alvarado-Flores, J., R. Rico-Martínez, A. Adabache-Ortíz \& M. Silva-Briano, 2015. Morphological alterations in the freshwater rotifer Brachionus calyciflorus Pallas 1766 (Rotifera: Monogononta) caused by vinclozolin chronic exposure. Ecotoxicology 24: 915-925. 
Angert, A. L., T. E. Huxman, P. Chesson \& D. L. Venable, 2009. Functional tradeoffs determine species coexistence via the storage effect. Proceedings of the National Academy of Sciences 106: 11641-11645.

Arthofer, W., H. Rauch, B. Thaler-Knoflach, K. Moder, C. Muster, B. Schlick-Steiner \& F. M. Steiner, 2013. How diverse is Mitopus morio? Integrative taxonomy detects cryptic species in a small-scale sample of a widespread harvestman. Molecular Ecology 22: 3850-3863.

Barraclough, T. G., D. Fontaneto, C. Ricci \& E. A. Herniou, 2007. Evidence for inefficient selection against deleterious mutations in cytochrome oxidase I of asexual bdelloid rotifers. Molecular Biology and Evolution 24: 1952-1962.

Begon, M., M. Mortimer \& D. J. Thompson, 1996. Population ecology: a unified study of plants and animals. Blackwell Science Ltd., Oxford.

Berg, L. M., 2005. Fluctuating selection, egg banks and population genetic structure in cyclically parthenogenetic species. Hydrobiologia 549: 287-295.

Birch, L., 1948. The intrinsic rate of natural increase of an insect population. The Journal of Animal Ecology 17: 15-26.

Birky Jr., C. W., C. Ricci, G. Melone \& D. Fontaneto, 2011. Integrating DNA and morphological taxonomy to describe diversity in poorly studied microscopic animals: new species of the genus Abrochtha Bryce, 1910 (Rotifera: Bdelloidea: Philodinavidae). Zoological Journal of the Linnean Society 161: 723-734.

Bogoslavsky, A. S., 1958. New observations concerning the reproduction of rotifers. Observations on Sinantherina socialis. Zoologicheskii Zhurnal 37: 1616-1623.

Bogoslavsky, A. S., 1960. Observations on the reproduction of Conochiloides coenobasis Skorikov and the statement of a physiological category of females new to heterogonous Rotifera. Zoologicheskii Zhurnal 39: 670-677.

Bottrell, H. H., A. Duncan, Z. M. Gliwicz, E. Grygierek, A. Herzig, A. Hillbricht-Ilkowska, H. Kurasawa, P. Larsson \& T. Weglenska, 1976. A review of some problems in zooplankton production studies. Norwegian Journal of Zoology 24: 419-456.

Campillo, S., E. M. García-Roger, M. J. Carmona \& M. Serra, 2011. Local adaptation in rotifer populations. Evolutionary Ecology 25: 933-947.

Carmona, M. J., M. Serra \& M. R. Miracle, 1993. Relationships between mixis in Brachionus plicatilis and preconditioning of culture medium by crowding. Hydrobiologia 255: $145-152$.

Cieplinski, A., T. Weisse \& U. Obertegger, 2017. High diversity in Keratella cochlearis (Rotifera, Monogononta): morphological and genetic evidence. Hydrobiologia 796: 145-159.

Ciros-Pérez, J., A. Gomez \& M. Serra, 2001. On the taxonomy of three sympatric sibling species of the Brachionus plicatilis (Rotifera) complex from Spain, with the description of B. ibericus n. sp. Journal of Plankton Research 23: 1311-1328.

Darwin, C., 1859. On the Origin of Species by Means of Natural Selection, or Preservation of Favoured Races in the Struggle for Life. John Murray, London.

Desmarais, K. H., 1997. Keeping Daphnia out of the surface film with cetyl alcohol. Journal of Plankton Research 19: 149-154.
Dixon, P. M., 2002. Bootstrap Resampling. Encyclopedia of Environmetrics, Vol. 1. Wiley, Chichester: 212-220.

Edmondson, W. T., 1965. Reproductive Rate of Planktonic Rotifers as Related to Food and Temperature in Nature. Ecological Monographs 35: 61-111

Foissner, W., 2006. Biogeography and dispersal of micro-organisms: a review emphasizing protists. Acta Protozoologica 45: 111-136.

Fontaneto, D., M. Kaya, E. A. Herniou \& T. G. Barraclough, 2009. Extreme levels of hidden diversity in microscopic animals (Rotifera) revealed by DNA taxonomy. Molecular Phylogenetics and Evolution 53: 182-189.

Fontaneto, D., J. F. Flot \& C. Q. Tang, 2015. Guidelines for DNA taxonomy, with a focus on the meiofauna. Marine Biodiversity 45: 1-19.

Fournier, D., M. Tindo, M. Kenne, P. S. M. Masse, V. Van Bossche, E. De Coninck \& S. Aron, 2012. Genetic structure, nestmate recognition and behaviour of two cryptic species of the invasive big-headed ant Pheidole megacephala. PloS One 7: e31480.

Gabaldón, C. \& M. J. Carmona, 2015. Allocation patterns in modes of reproduction in two facultatively sexual cryptic rotifer species. Journal of Plankton Research 37: 429-440.

Gabaldón, C., M. Serra, M. J. Carmona \& J. Montero-Pau, 2015. Life-history traits, abiotic environment and coexistence: the case of two cryptic rotifer species. Journal of Experimental Marine Biology and Ecology 465: 142-152.

Gabaldón, C., D. Fontaneto, M. J. Carmona, J. Montero-Pau \& J. M. Serra, 2017. Ecological differentiation in cryptic rotifer species: what we can learn from the Brachionus plicatilis complex. Hydrobiologia 796: 7-18.

Gilbert, J. J., 1995. Structure, development and induction of a new diapause stage in rotifers. Freshwater Biology 34: 263-270.

Gilbert, J. J. \& R. S. Stemberger, 1985. Control of Keratella populations by interference competition from Daphnia. Limnology and Oceanography 30: 180-188.

Gomez, A. \& T. W. Snell, 1996. Sibling species and cryptic speciation in the Brachionus plicatilis species complex (Rotifera). Journal of Evolutionary Biology 9: 953-964.

Gomez, A., M. Serra, G. R. Carvalho \& D. H. Lunt, 2002. Speciation in ancient cryptic species complexes: evidence from the molecular phylogeny of Brachionus plicatilis (Rotifera). Evolution 56: 1431-1444.

Gomez, A., J. Montero-Pau, D. H. Lunt, M. Serra \& S. Campillo, 2007. Persistent genetic signatures of colonization in Brachionus manjavacas rotifers in the Iberian Peninsula. Molecular Ecology 16: 3228-3240.

Gribble, K. E. \& D. B. M. Welch, 2013. Life-span extension by caloric restriction is determined by type and level of food reduction and by reproductive mode in Brachionus manjavacas (Rotifera). Journals of Gerontology Series A: Biomedical Sciences and Medical Sciences 68: 349-358.

Guillard, R. R. \& C. J. Lorenzan, 1972. Yellow-green algae with chlorophyllide C. Journal of Phycology 8: 10-14.

Henry, L., T. Schwander \& B. J. Crespi, 2011. Deleterious mutation accumulation in asexual Timema stick insects. Molecular Biology and Evolution 29: 401-408.

Hu, H. \& Y. Xi, 2008. Demographic parameters and mixis of three Brachionus angularis Gosse (Rotatoria) strains fed 
on different algae. Limnologica-Ecology and Management of Inland Waters 38: 56-62.

Keen, R. \& T. Miller, 1977. Daily timing of hatching of a rotifer, Keratella cochlearis. Hydrobiologia 56: 127-128.

King, C. E., 1970. Comparative survivorship and fecundity of mictic and amictic female rotifers. Physiological Zoology 43: 206-212.

King, C. E. \& T. W. Snell, 1977. Genetic basis of amphoteric reproduction in rotifers. Heredity 39: 361-364.

Korstad, J., Y. Olsen \& O. Vadstein, 1989. Life history characteristics of Brachionus plicatilis (Rotifera) fed different algae. Hydrobiologia 186: 43-50.

Koste, W. \& E. D. Hollowday, 1993. A short history of western European rotifer research. Hydrobiologia 255: 557-572.

Kostopoulou, V. \& O. Vadstein, 2007. Growth performance of the rotifers Brachionus plicatilis, B. 'Nevada' and B. 'Cayman' under different food concentrations. Aquaculture 273: 449-458.

Leibold, M. A. \& M. A. McPeek, 2006. Coexistence of the niche and neutral perspectives in community ecology. Ecology 87: $1399-1410$.

Lindström, K. \& B. Pejler, 1975. Experimental studies on the seasonal variation of the rotifer Keratella cochlearis (Gosse). Hydrobiologia 46: 191-197.

Losos, J. B., 2008. Phylogenetic niche conservatism, phylogenetic signal and the relationship between phylogenetic relatedness and ecological similarity among species. Ecology Letters 11: 995-1003.

Lotka, A. J., 1907. Studies on the mode of growth of material aggregates. American Journal of Science 141: 199-216.

Lynch, M. \& R. Ennis, 1983. Resource availability, maternal effects, and longevity. Experimental Gerontology 18: 147-165.

Lynch, M., J. Blanchard, D. Houle, T. Kibota, S. Schultz, L. Vassilieva \& J. Willis, 1999. Perspective: spontaneous deleterious mutation. Evolution 53: 645-663.

Ma, Q., Y. L. Xi, J. Y. Zhang, X. L. Wen \& X. L. Xiang, 2010. Differences in life table demography among eight geographic populations of Brachionus calyciflorus (Rotifera) from China. Limnologica-Ecology and Management of Inland Waters 40: 16-22.

McCullough, J. D. \& R. D. Lee, 1980. An ecological study of the rare rotifer species Trochosphaera solstitialis (Thorpe 1893) and the first report of the male. Hydrobiologia 71: $7-18$.

Meyer, J. S., C. G. Ingersoll, L. L. McDonald \& M. S. Boyce, 1986. Estimating uncertainty in population growth rates: jackknife vs. bootstrap techniques. Ecology 67: 1156-1166.

Montero-Pau, J., E. Ramos-Rodríguez, M. Serra \& A. Gomez, 2011. Long-term coexistence of rotifer cryptic species. PLoS ONE 6: e21530.

Mrázek, A., 1897. Zur Embryonalentwicklung der Gattung Asplanchna. Sitzungsber. Königliche böhmische Gesellschaft der Wissenschaften. Mathematisch-Naturwissenschaftliche Classe 58: 1-11

Obertegger, U., D. Fontaneto \& G. Flaim, 2012. Using DNA taxonomy to investigate the ecological determinants of plankton diversity: explaining the occurrence of Synchaeta spp. (Rotifera, Monogononta) in mountain lakes. Freshwater Biology 57: 1545-1553.
Obertegger, U., G. Flaim \& D. Fontaneto, 2014. Cryptic diversity within the rotifer Polyarthra dolichoptera along an altitudinal gradient. Freshwater Biology 59: 2413-2427.

Obertegger, U. \& G. Flaim, 2015. Community assembly of rotifers based on morphological traits. Hydrobiologia 753: 31-45.

Obertegger, U., A. Cieplinski, D. Fontaneto \& S. Papakostas, 2017. Mitonuclear discordance as a confounding factor in the DNA taxonomy of monogonont rotifers. Zoologica Scripta 47: 122-132.

Olson-Manning, C. F., M. R. Wagner \& T. Mitchell-Olds, 2012. Adaptive evolution: evaluating empirical support for theoretical predictions. Nature reviews. Genetics 13: 867-877.

Papakostas, S., E. Michaloudi, K. Proios, M. Brehm, L. Verhage, J. Rota, C. Peña, G. Stamou, V. L. Pritchard, D. Fontaneto \& S. A. Declerck, 2016. Integrative taxonomy recognizes evolutionary units despite widespread mitonuclear discordance: evidence from a rotifer cryptic species complex. Systematic Biology 65: 508-524.

Pourriot, R., 1965. Recherches sur l'écologie des rotifères. Vie Milieu (suppl.) 21: 1-224.

Pourriot, R., 1980. Workshop on culture techniques of rotifers. Hydrobiologia 73: 33-35.

Quinn, G. P. \& M. J. Keough, 2002. Experimental Design and Data Analysis for Biologists. Cambridge University Press, Cambridge.

R Core Team, 2017. R: a language and environment for statistical computing. R Foundation for Statistical Computing, Vienna. http://www.rproject.org.

Rico-Martínez, R. \& E. J. Walsh, 2013. Sexual Reproductive Biology of a Colonial Rotifer Sinantherina socialis (Rotifera: Monogononta): Do mating strategies vary between colonial and solitary rotifer species? Marine and Freshwater Behaviour and Physiology 46: 419-430.

Ridley, M., 2008. Evolution, 2nd ed. Malden - Blackwell Scientific Publishing, Massachusetts.

Rios-Arana, J. V., E. J. Walsh \& M. Ortiz, 2007. Interaction effects of multi-metal solutions (As, $\mathrm{Cr}, \mathrm{Cu}, \mathrm{Ni}, \mathrm{Pb}$ and $\mathrm{Zn}$ ) on life history traits in the rotifer Plationus patulus. Journal of Environmental Science and Health Part A 42: 1473-1481.

Robertson, J. R. \& G. W. Salt, 1981. Responses in growth mortality, and reproduction to variable food levels by the rotifer, Asplanchna girodi. Ecology 62: 1585-1596.

Ruttner-Kolisko, A., 1946. Über das Auftreten unbefruchteter 'Dauereier'bei Anuraea aculeata (Keratella quadrata). Österreichische Zoologische Zeitschrift 1: 179-191.

Sarma, S. S. S., S. Nandini \& J. L. G. Flores, 2001. Effect of methyl parathion on the population growth of the rotifer Brachionus patulus (OF Müller) under different algal food (Chlorella vulgaris) densities. Ecotoxicology and Environmental Safety 48: 190-195.

Schlick-Steiner, B. C., F. M. Steiner, B. Seifert, C. Stauffer, E. Christian \& R. H. Crozier, 2010. Integrative taxonomy: a multisource approach to exploring biodiversity. Annual review of Entomology 55: 421-438.

Segers, H. \& W. H. De Smet, 2008. Diversity and endemism in Rotifera: a review, and Keratella Bory de St Vincent. Biodiversity and Conservation 17: 303-316. 
Snell, T. W., J. Kubanek, W. Carter, A. B. Payne, J. Kim, M. K. Hicks \& C. P. Stelzer, 2006. A protein signal triggers sexual reproduction in Brachionus plicatilis (Rotifera). Marine Biology 149: 763-773.

Sommaruga, R., 2001. The role of solar UV radiation in the ecology of alpine lakes. Journal of Photochemistry and Photobiology B: Biology 62: 35-42.

Stearns, S. C., 1992. The Evolution of Life Histories, Vol. 249. Oxford University Press, Oxford.

Stelzer, C. P., 1998. Population growth in planktonic rotifers. Does temperature shift the competitive advantage for different species? Hydrobiologia 387: 349-353.

Stelzer, C. P. \& T. W. Snell, 2003. Induction of sexual reproduction in Brachionus plicatilis (Monogononta, Rotifera) by density-dependant chemical cue. Limnology and Oceanography 48: 939-943.

Stelzer, C. P. \& T. W. Snell, 2006. Specificity of the crowding response in the Brachionus plicatilis species complex. Limnology and Oceanography 51: 125-130.

Stemberger, R. S., 1981. A general approach to the culture of planktonic rotifers. Canadian Journal of Fisheries and Aquatic Sciences 38: 721-724.

Stemberger, R. S. \& J. J. Gilbert, 1985. Body size, food concentration, and population growth in planktonic rotifers. Ecology 66: 1151-1159.

Sudzuki, M., 1955. On the general structure and the seasonal occurrence of the males in some Japanese rotifers. III. Zoological Magazine 64: 189-193.

Sun, D. \& C. Niu, 2012. Maternal crowding can enhance the propensity of offspring to produce mictic females in the rotifer Brachionus calyciflorus. Journal of Plankton Research 34: 732-737.

Violle, C., D. R. Nemergut, Z. Pu \& L. Jiang, 2011. Phylogenetic limiting similarity and competitive exclusion. Ecology Letters 14: 782-787.

Walz, N., 1983. Individual culture and experimental population dynamics of Keratella cochlearis (Rotatoria). Hydrobiologia 107: 35-45.

Walz, N., 1986. Wie werden Rotatorienpopulationen reguliert? Beziehungen zwischen Rotatorien. Crustaceen, und Phytoplankton. In: Siedebeck, O. (ed), Elemente der Steuerung und der Regulation in der Pelagialbiozönose. Akademie für Naturschutz und Landschaftpflege. Laufener Seminarbeitr 2/86: 80-90.

Walz, N., 1987. Comparative population dynamics of the rotifers Brachionus angularis and Keratella cochlearis. Hydrobioogia 147: 209-213.

Walz, N., 1995. Rotifer populations in plankton communities: energetics and life history strategies. Experientia 51: $437-453$.

Wallace, R. L., T. W. Snell, C. Ricci \& T. Nogrady, 2006. Rotifera. Vol. 1. Biology, Ecology and Systematics. In
Segers, H. and Dumont, H. J. (eds), Guides to the Identification of the Microinvertebrates of the Continental Waters of the World, 2nd edn. Kenobi Productions, Gent.

Wang, X. L., X. L. Xiang, M. N. Xia, Y. Han, L. Huang \& Y. L. Xi, 2014. Differences in life history characteristics between two sibling species in Brachionus calyciflorus complex from tropical shallow lakes. Annales de Limnologie-International Journal of Limnology 50: 289-298.

Weckström, K., J. Weckström, K. Huber, C. Kamenik, R. Schmidt, W. Salvenmoser, M. Rieradevall, T. Weisse, R. Psenner \& R. Kurmayer, 2016. Impacts of climate warming on Alpine lake biota over the past decade. Arctic, Antarctic, and Alpine Research 48: 361-376.

Weisse, T. \& B. Kirchhoff, 1997. Feeding of the heterotrophic freshwater dinoflagellate Peridiniopsis berolinense on cryptophytes: analysis by flow cytometry and electronic particle counting. Aquatic Microbial Ecology 12: 153-164.

Weisse, T. \& A. Frahm, 2001. Species-specific interactions between small planktonic ciliates (Urotricha spp.) and rotifers (Keratella spp.). Journal of Plankton Research 23: 1329-1338.

Wesenberg-Lund, C., 1923. Contributions to the Biology of the Rotifera, Vol. 1. AF Høst \& søn, Copenhagen.

Wiens, J. J. \& C. H. Graham, 2005. Niche conservatism: integrating evolution, ecology, and conservation biology. Annual Review of Ecology, Evolution, and Systematics 36: 519-539.

Xi, Y.\& X. Huang, 1999. Effects of both algae components and densities on the formation of resting eggs of the freshwater rotifer, Brachionus calyciflorus. Dong wu xue bao [Acta Zooogica. Sinnica] 46: 27-36.

Xiang, X.-L., Y.-Y. Chen, Y. Han, X.-L. Wang \& Y.-L. Xi, 2016a. Comparative studies on the life history characteristics of two Brachionus calyciflorus strains belonging to the same cryptic species. Biochemical Systematics and Ecology 69: 138-144.

Xiang, X., R. Jiang, Y. Tao, Y. Chen \& Y. Xi, 2016b. Differences in life history characteristics among three sympatric evolutionary species of the Rotaria rotatoria complex. Journal of Freshwater Ecology 31: 351-360.

Xi, Y.-L., D.-D. Xu, J. Ma, Y.-L. Ge \& X.-L. Wen, 2013. Differences in life table parameters between Keratella tropica and Keratella valga (Rotatoria) from subtropical shallow lakes. Journal of Freshwater Ecology 28: 539-545.

Zimmermann, C., 1974. Die pelagischen Rotatorien des Sempachersees, mit spezieller Berücksichtigung der Brachioniden und der Ernährungsfrage. Aquatic SciencesResearch Across Boundaries 36: 205-300.

Żurek, R., 2006. Response of rotifers to hydrochemical and biotic factors. Oceanological and Hydrobiological Studies 35: 121-139. 